\title{
¿Una represa hidroeléctrica sobre el río San Juan? (Artículo informativo)
}

\author{
An hydroelectrical dam in the San Juan \\ River? (Informative article)
}

Jean Pierre Bergoeing Guida'

Fecha de recepción: 20 de enero del 2012

Fecha de aprobación: 19 de marzo del 2012

Bergoeing, J. ¿Una represa hidroeléctrica sobre el río San Juan? Tecnología en Marcha. Vol. 25, № 5.

Pág $81-85$. 


\section{Palabras clave}

Geomorfología, represa hidroeléctrica.

\section{Resumen}

El autor utiliza el mapa geomorfológico del sector fronterizo al San Juan para indicar las consecuencias que un proyecto hidroeléctrico en el río San Juan tendría para el sector fronterizo con Costa Rica por la subida de las aguas represadas.

\section{Key words}

Geomorphology, hydroelectric dam.

\section{Abstract}

The author uses the geomorphological map of the San Juan River border sector to indicate the consequences for the border area with Costa Rica by the waters rising of the San Juan river hydroelectrical project.

\section{Introducción}

Desde hace un tiempo se viene evocando el proyecto hidroeléctrico de construcción de una represa sobre el río San Juan, aproximadamente a unos 17 $\mathrm{km}$ de la boca del río con el lago de Nicaragua.

La creación de una represa hidroeléctrica en el río san Juan es en sí una obra de ingeniería civil de grandes proporciones, que presupone una inversión considerable a la que solo se puede acceder con fondos extranjeros, ya que Nicaragua no tiene la capacidad financiera para emprender un proyecto de tal envergadura económica.

Para Nicaragua, significaría evidentemente una fuente de suministro hidroeléctrico de primer orden, que le permitiría desarrollar industrias y empresas en su territorio y ya no depender de sus viejas centrales térmicas ni de la compra de electricidad a Costa Rica.

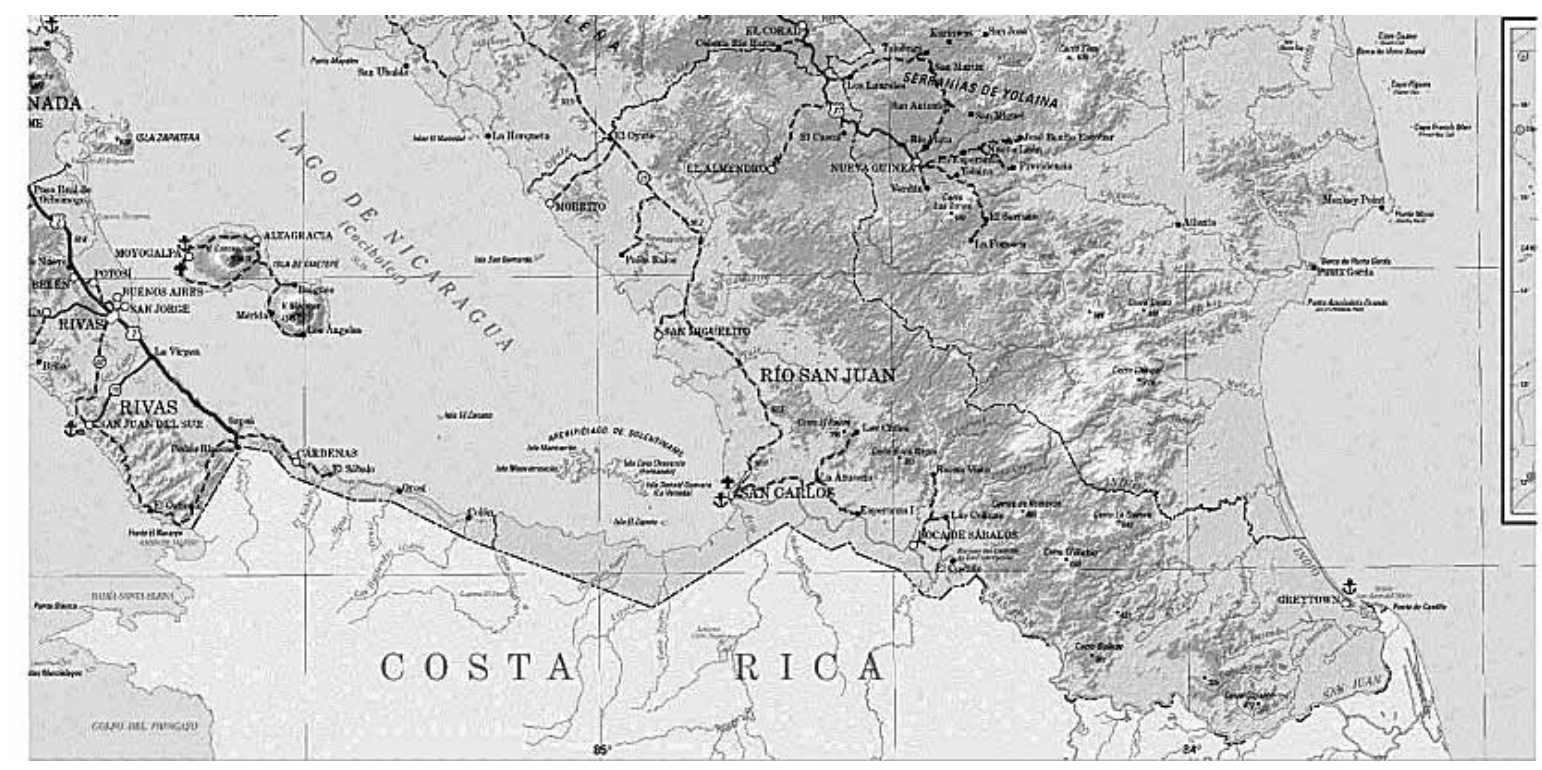

Figura I. Carta topográfica del sector fronterizo de Costa Rica con Nicaragua. INETER, Nicaragua. 


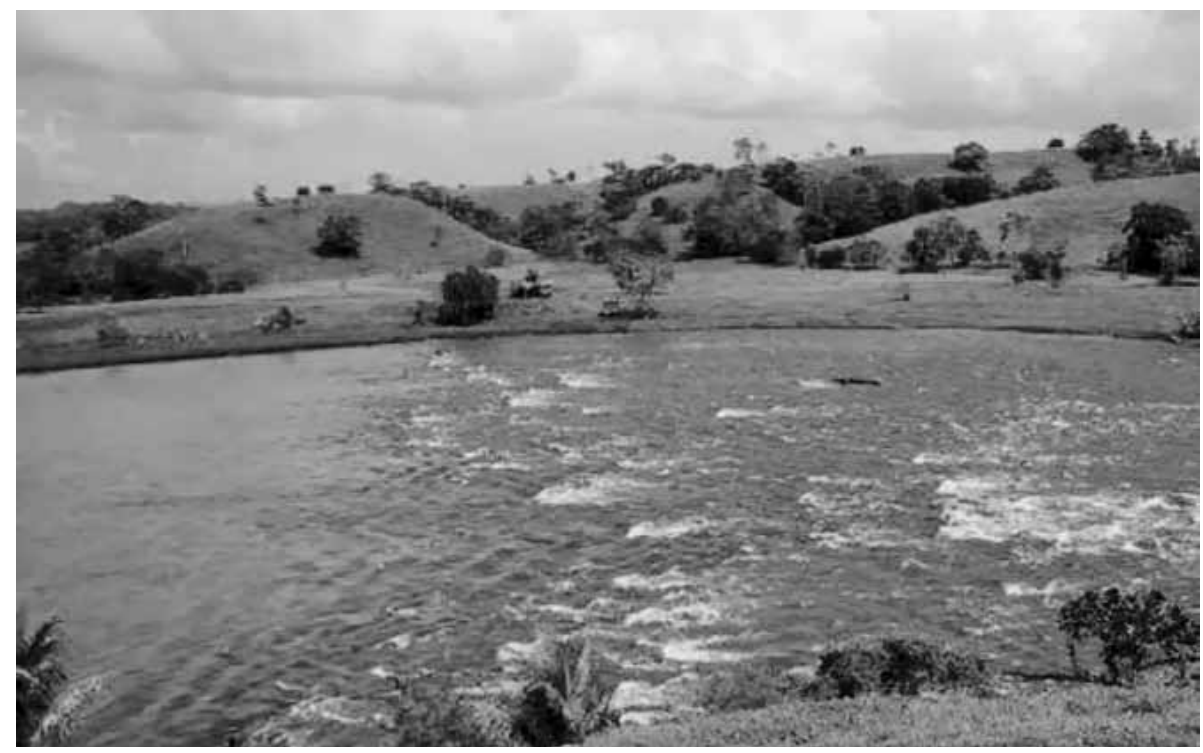

Figura 2. Rápidos sobre el río San Juan de Nicaragua a la altura de El Castillo. La tectónica positiva ha levantado el lecho del río, con lo cual se crearon los rápidos en un sector que era navegable en 1856 por los pequeños vapores de la compañía Vanderbilt.

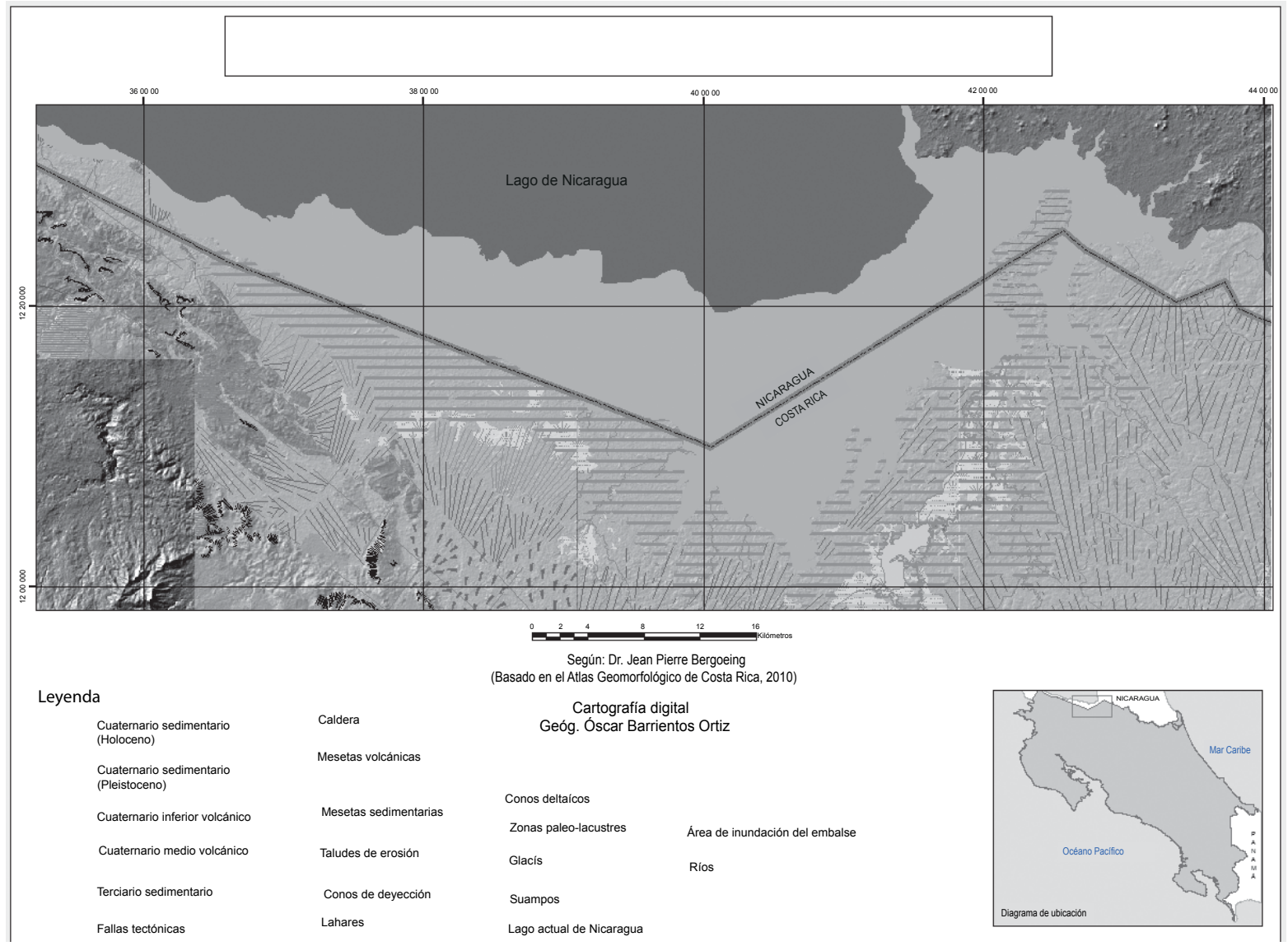

Figura 3. En color celeste se observa el área que quedaría inundada por efecto de la represa hidroeléctrica sobre el río San Juan. Extracto del mapa geomorfológico modificado de Bergoeing et al., 2010. 
Sin embargo, tal proyecto conlleva problemas de diversas índoles, ambientales y diplomáticas, que hay que resolver prioritariamente antes de iniciar cualquier estudio conducente a la construcción de ese megaproyecto, que tardaría por lo menos diez años en su ejecución.

\section{La cota de los 30 metros}

Al realizar una cartografía a escala 1:50 000 de lo que significaría el área de embalse, tomando como límite del llenado de aguas represadas la cota de 30 metros de altitud, nos percatamos inmediatamente de que no solo quedarían inundadas grandes áreas de Nicaragua, como la ciudad de San Carlos, sino que también en Costa Rica habrían grandes áreas sumergidas por el nuevo nivel del lago. Por ello, los puntos por resolver serían los siguientes:

I. Revisión con autorización de Costa Rica del Tratado de límites Cañas-Jerez, por cuanto la actual frontera desaparecería en parte, sumergida por la subida de las aguas del lago, dándole a Costa Rica una nueva frontera lacustre con el lago de Nicaragua.

2. Desaparición de los grandes humedales del sector de Caño Negro y de terrenos agropecuarios costarricenses (sin mencionar la mayoría de los terrenos nicaragüenses contiguos al lago).

3. Indemnización inmediata por parte de Nicaragua a los propietarios costarricenses afectados por la subida de las aguas, así como al Estado costarricense por la pérdida de sus humedales.

\section{Conclusión}

El proyecto nicaragüense de construcción de una represa hidroeléctrica en el río (que debería construirse entre San Carlos y El Castillo donde ambas márgenes son nicaragüenses), mermaría considerablemente su caudal en su curso inferior y por lo tanto la del río Colorado, vía fluvial turística de gran importancia para Costa Rica. Ello nos conduce al Derecho Internacional Fluvial.

En efecto, si Nicaragua desea hacer obras de retención o desvío de aguas sobre el San Juan es en virtud de su plena soberanía sobre este río, con lo cual se desvincula del Derecho Internacional Fluvial.
Aceptando este criterio, Costa Rica también tendría todo el derecho de crear un canal paralelo al San Juan, a unos $5 \mathrm{~km}$ del mismo, desviando las aguas de los ríos afluentes que nacen en Costa Rica, a partir del río San Carlos, para hacerlos confluir al río Colorado, aumentando con ello su caudal.

Con ello se crearía un sistema de navegación fluvial dentro de su propio territorio, favoreciendo el desarrollo turístico y agrícola del sector sin las actuales trabas de los patrullajes nicaragüenses del río San Juan.

También se podría construir una carretera en la franja resultante entre el San Juan y el nuevo canal, que podría ser patrullada por la policía de fronteras.

Todo esto se podría obviar si entre Nicaragua y Costa Rica prevaleciera un clima de entendimiento, al cual están obligados a llegar por la geografía que los condiciona y en donde se pudieran explotar los recursos de la cuenca hidrográfica del río San Juan, con el debido respeto de la soberanía de ambos países desde el punto de vista turístico, agrícola, hidroeléctrico y comercial. No cabe duda de que ambos países saldrían ganando.

Para poder hacer factible el proyecto de una represa hidroeléctrica de tal envergadura sobre el San Juan de Nicaragua, es preciso tomar en cuenta la totalidad de la cuenca hidrográfica y ello, lógicamente, incluye a Costa Rica como socio obligado en un proyecto de desarrollo hidroeléctrico muy importante, no cabe la menor duda, pero con consecuencias humanas (traslado de poblados enteros en ambas partes de las márgenes fluviales y lacustres, pérdida de terrenos agropecuarios y construcción de nuevas carreteras), ecológicas (desaparición de humedales y bosques primarios y secundarios) y políticas (nuevo trazado y paisaje transfronterizo).

Por todo ello, un desarrollo unilateral por parte de Nicaragua está condenado a un total fracaso, puesto que conlleva directamente la alteración del tratado de límites Cañas Jerez.

\section{Bibliografía}

Bergoeing, J.P. (2007). Geomorfología de Costa Rica. San José: Librería Francesa.

Bergoeing, J.P.; Arce, R.; Brenes, L.G. \& Protti, R. (20|0). Atlas Geomorfológico de la Vertiente del Caribe de Costa 
Rica, escala 1:100.000. San José: Editorial Universidad de Costa Rica.

Bergoeing, J.P.; Brenes; L.G.; Salas; D. (20 I 0). Atlas Geomorfológico de Costa Rica. Escala 1:350.000. San José: Instituto Costarricense de Electricidad.

Organización de las Naciones Unidas (ONU) (2007). Reports of international arbitral awards. Reccueil des sentences arbitrales. First award under the Convention between Costa Rica and Nicaragua of 8 April 1896 for the demarcation of the boundary between the two Republics 30 September I 897 Volume XXXVIII pp. 2 I 5-222 Nations Unies - United Nations.

Periódico La República. Grandes represas, cambio climático y desalojos forzados. Obtenido desde: http://www.wrn.org.uy/ boletin/90/represasyCC.html 